\title{
Do early life and contemporaneous macroconditions explain health at older ages?
}

\section{An application to functional limitations of Dutch older individuals}

\section{France Portrait • Rob Alessie • Dorly Deeg}

Received: 9 June 2005 / Accepted: 6 June 2008 /

Published online: 29 August 2008

(C) The Author(s) 2008. This article is published with open access at Springerlink.com

\begin{abstract}
This paper presents an approach that assesses the role of early life and contemporaneous macroconditions in explaining health at older ages. In particular, we investigate the role of exposure to diseases and economic conditions during infancy and childhood, as well as the effect of current health care facilities. Specific attention is paid to the impact of unobserved heterogeneity, selective attrition, and omitted relevant macrovariables. We apply our approach to self-reports on functional limitations of Dutch older individuals. The prevalence of functional limitations is found to increase in the 1990s, in part due to restricted access to hospital care.
\end{abstract}

\section{Responsible editor: Christian Dustmann}

F. Portrait $(\bowtie)$

Institute for Health Sciences, VU University Amsterdam room U451,

De Boelelaan 1085, 1081 HV Amsterdam, The Netherlands

e-mail: france.portrait@falw.vu.nl

F. Portrait · R. Alessie

Tinbergen Institute, Amsterdam, The Netherlands

R. Alessie

Utrecht School of Economics, Utrecht University, Utrecht, The Netherlands

R. Alessie

Netspar, Tilburg, The Netherlands

D. Deeg

Longitudinal Aging Study Amsterdam, Institute for Research in Extramural Medicine,

VU University Amsterdam Medical Center, Amsterdam, The Netherlands 
Keywords Early life macroconditions - Contemporaneous macroconditions • Functional limitations

JEL Classification $\mathrm{I} 12 \cdot \mathrm{J} 11 \cdot \mathrm{J} 17$

\section{Introduction}

A growing body of evidence shows the importance of early life environmental conditions in explaining health at old ages. For instance, individuals who faced nutritional and/or pathological stresses during pregnancy or the first years of life are more likely to experience worse health conditions and higher mortality rates at older ages (Fridlizius 1989; Barker 1998; Roseboom 2001; Fogel 1994; Almond 2006; see Kuh and Ben-Shlomo 2004 for a comprehensive review of the epidemiological evidence). Furthermore, research shows that individuals born in recessions face higher mortality rates later in life (van den Berg et al. 2006). On the other hand, current health care and economics may have important consequences for health as well (Mackenbach 1996; van den Berg et al. 2006; Ruhm 2008, in press). The focus of the present study is to assess the role of early life and current macroconditions in explaining health at old ages, controlling for a large range of individual characteristics.

Clearly, when studying the relationships between macroconditions and health, information on some early life and current macrodeterminants may be lacking. This may be particularly true in a study on old people since data are required that refer to historical periods. Excluding possibly important macrovariables may result in spurious associations between health and the included macroconditions. In addition, genetic factors or inherent frailty of the individuals are important determinants of health and are most often not observed. This may also induce biases in the parameters of interest. The paper develops and applies an estimation strategy to better control for sources of omitted variables bias in the context of a health study. We will return to the estimation strategy in more detail in Section 2.

Our method is applied to the study of functional limitations of older Dutch individuals. Functional limitations are restrictions in performing physical actions used in daily life. Functional status is an important aspect of the healthrelated quality of life of older individuals and strongly associated with the use of health care services. In the 1990s, the Netherlands faced increasing trends in functional limitations at older ages (Hoeymans et al. 1997; Perenboom et al. 2004). Our study may provide insights into the mechanisms explaining these trends. Especially in the context of aging populations, increasing trends in functional limitations may put extra pressure on the already congested Dutch health care market.

The analyses are performed using data from the Longitudinal Aging Study Amsterdam (LASA), an ongoing study that follows a representative sample 
of Dutch older individuals (Deeg and Westendorp de Serière 1994; Deeg et al. 1998). For the study at hand, we use the first three waves, conducted in 1992-1993, in 1995-1996, and in 1998-1999. The data set contains detailed individual health information. Statistics Netherlands provides information on the macroconditions. We use epidemiologic and economic theory as well as empirical evidence to identify the macroconditions that may affect health at older ages.

The major advantage of panel data is that we can take into account unobserved heterogeneity. However, panel data, specifically on older populations, may suffer from selective attrition due to mortality or refusals. The paper corrects for the effects of selective attrition. Finally, we include a variety of statistical checks to assess the validity of our results; particularly, we tested whether the effects of the early life and contemporaneous conditions are correctly modeled.

Our study is related to the line of research that tackles the basic identification problem of the age, period, and cohort (APC) effects. The contemporaneous macroconditions refer to period effects. The macroconditions that cohorts have faced in early life refer to cohort effects. In the APC literature, age effects are usually characterized by age of the individual, period effects by the calendar year during which the period effects take place, and cohort effects by the year of birth of the relevant cohorts. Clearly, identification of such effects is problematic because of the impossibility of observing individuals of the same age in the same calendar year but born in different years. Indeed, APC effects are perfectly linearly related as year of birth plus age equals calendar year. The usual way out to handle the perfect collinearity is to restrict the parameters of the model (Mason and Fienberg 1985; Reynolds et al. 1998; Alwin and McCammon 2001). Therefore, the coefficients are identified on the basis of functional form assumptions that cannot be tested (Mason and Fienberg 1985). Moreover, dummies are very poor proxies for the unobserved underlying effects and are not informative about the causal mechanisms underlying the effects of early life and contemporaneous macroconditions on mortality (Heckman and Robb 1985). Our approach is to replace the dummies by observed variables that more directly explain the mechanisms at hand. This has two main advantages: to handle the APC identification problem and to reveal some of the mechanisms explaining health at older ages. The "modeling approach" is the approach suggested by Nydegger (1981) and Heckman and Robb (1985). To our knowledge, this approach is innovative in the literature on health and has seldom been applied in other areas (for a recent economic application of the method, see Kapteyn et al. 2005). Note further that we explicitly model cohort and period effects and that we correct for selective attrition. As far as we know, this has not been done before in the APC literature.

The remainder of this paper is organized as follows: The estimation strategy is presented in more detail in Section 2. In particular, we discuss the impact of unobserved heterogeneity, selective attrition, and omitted macrovariables on the estimation results. Section 3 describes the data. Section 4 reports the 
estimation results. Section 5 presents the results of the sensitivity analyses. Finally, a summary and a conclusion is given in Section 6.

\section{Estimation method}

\subsection{Model}

Assume a panel data set that includes $I$ respondents at baseline and $T$ waves. After pooling the data of the $T$ waves together, we can express the health status indicator $H$ as a function of a vector of individual socioeconomic and demographic background characteristics $x$, age $a$, the current macroconditions $\mathrm{PV}$, and the macroconditions earlier in life CV:

$$
H_{i}^{t}=\alpha+x_{i}^{t}, \beta+\sum_{k=1}^{K_{1}} \mathrm{CV}_{i, k} \gamma_{k}+\sum_{k=1}^{K_{2}} \mathrm{PV}_{k}^{t} \delta_{k}+\sum_{k=1}^{K_{3}-1} f_{k}\left(a_{i}^{t}\right) \zeta_{k}+v_{i}^{t}
$$

$K_{1}$ refers to the number of included early life indicators and $K_{2}$ refers to the number of the included contemporaneous indicators. The relationship between $H_{i}^{t}$ and age is modeled by means of a linear spline function with $K_{3}$ knots, which splits the whole age range into $K_{3}-1$ intervals. The coefficients $\zeta_{k}$ corresponding to the $K_{3}-1$ spline variables $f_{k}\left(a_{i}^{t}\right)$ are the age interval specific slopes. Note that modeling age using a full set of age dummies is the most flexible way of modeling the effects of age. However, to save some degrees of freedom, we opted for a linear spline function in age. $\alpha, \beta, \gamma_{k}$ for $k$ running from 1 until $K_{1}, \delta_{k}$ for $k$ running from 1 until $K_{2}$, and $\zeta_{k}$ for $k$ running from 1 until $K_{3}$ are the parameters to be estimated and $v_{i}^{t}$ is the error term.

Identification of the model rests upon the assumption that the macroindicators of early conditions do not depend linearly on the variable year of birth and the macroindicators for the contemporaneous conditions do not depend linearly on the calendar year. Note additionally that the necessary conditions for identification of model Eq. 1 are that $K_{1}$ should be smaller than the total number of cohorts minus 2 and $K_{2}$ must be smaller than the total number of periods minus 2 (Kapteyn et al. 2005).

As mentioned in Section 1, some macroinformation may be missing. Moreover, information on determinants of health such as genetic factors or inherent frailty is generally not available. An appropriate and rigorous treatment of the unobserved part is required if we want to trust the conclusions of the empirical analysis. This is the main focus of the next section. 


\subsection{Empirical specification}

\subsubsection{Unobserved individual effects}

Unobserved components such as genetic endowment or inherent frailty might induce an observed correlation between health and the health determinants. Model Eq. 1 should be adjusted for the impact of unobserved heterogeneity if we want to consistently estimate the included parameters. The error term $v_{i}^{t}$ is likely to be correlated with the right-hand-side variables. In order to get more insight into this correlation, we write $v_{i}^{t}$ as:

$$
v_{i}^{t}=c_{i}+u_{i}^{t}
$$

where $u_{i}^{t}$ is an idiosyncratic error term that might be correlated over time due to unanticipated permanent health shocks. Note that we do not control for state dependence in our analysis. This is because allowing for true state dependence would overcomplicate the analysis, especially if one allows for arbitrary autocorrelation structure in $u_{i}^{t}$.

The term $c_{i}$ reflects time-constant unobserved characteristics such as genetic factors or inherent frailty. The latter factors are determinants of health and may be correlated with demographic and socioeconomic characteristics of the individual $X_{i}^{t}\left(X_{i}^{t}\right.$, in contrast to $x_{i}^{t}$, include the early life and contemporaneous determinants, and the age linear spline variables): $E\left(c_{i} \mid X_{i}^{1}, \ldots X_{i}^{T}\right) \neq 0$. The right-hand variables in our health model are assumed to be strictly exogenous conditional on the unobserved effect $c_{i}$, i.e.:

$$
E\left(u_{i}^{t} \mid X_{i}^{1}, \ldots X_{i}^{T}, c_{i}\right)=0,
$$

which entails that the explanatory variables in each time period are uncorrelated with the idiosyncratic error term $u_{i}^{t}$.

We opt for a Mundlak approach (1978) to deal with the correlation between $c_{i}$ and the right-hand side variables by including in model Eq. 1 individual specific averages for the time-varying variables. In our context, Mundlak's approach boils down to the estimation of:

$$
H_{i}^{t}=\alpha+x_{i}^{t} \beta+\sum_{k=1}^{K_{1}} \mathrm{CV}_{i, k} \gamma_{k}+\sum_{k=1}^{K_{2}} \mathrm{PV}_{k}^{t} \delta_{k}+\sum_{k=1}^{K_{3}} f_{k}\left(a_{i}^{t}\right) \zeta_{k}+\overline{x_{i}^{\prime}} \pi+\omega_{i}+u_{i}^{t}
$$

where $\overline{x_{i}}$ refers to the individual specific averages for the time-varying variables and $\pi$ refers to the associated parameters. It is important to note that the remaining individual effect $\omega_{i}$ and the included regressors are assumed to be uncorrelated. 


\subsubsection{Attrition}

Panel data, especially on older populations, may suffer from selective attrition through mortality and refusals. As a result, an initially random sample may end up as a selective sample where the relatively healthy individuals are overor under-represented. This leads to inconsistent parameter estimates of the explanatory variables.

Our technique for testing and correcting for attrition bias follows the approach of Wooldridge (2002, chapter 17, sections 17.7.2 and 17.7.3) in a linear panel data model with unobserved heterogeneity. As a simple test for selective attrition, Wooldridge (2002, p. 581) suggests to include in the health equation a selection indicator, say $s_{i}^{t+1}$, equal to one if respondent $i$ participates in the study at $(t+1)$ and to zero if not. Under the null hypothesis - i.e., absence of selective attrition - the coefficient of the selection variable $s_{i}^{t+1}$ should not be significant (see Verbeek and Nijman 1992 for a similar approach).

Correcting for attrition bias is more complicated. We extend the method presented by Wooldridge (2002) in section 17.7.3 for a fixed effects approach to a random effects approach. Note that the method presented here treats attrition as an absorbing state, implying that respondents who leave the sample at $t$ do not reenter the sample at $\tau>t$. In our empirical study, attrition is indeed an absorbing state. In brief, the Wooldridge approach requires two equations that model the attrition between waves 1 and 2 and between waves 2 and 3, respectively. This is because we have three waves in our empirical study. Obviously, with more waves, we need more selection equations. From those selection equations, summary measures (namely inverse Mills ratios) can be constructed that summarize the information on attrition available in the selection equations. Finally, we estimate the health equations in which the summary measures are included (in order to correct for endogenous selection).

More formally, consider the following panel data model (using the same notation as before):

$$
H_{i}^{t}=X_{i}^{t} \theta+c_{i}+u_{i}^{t}
$$

where $\theta$ refers to the parameters associated with $X_{i}^{t}$. Conditional on $s_{i}^{t-1}=1$, write a (reduced form) selection equation for $t \geq 2$ as:

$$
s_{i}^{t}=1\left[z_{i}^{t} \eta_{t}+\mu_{i}^{t}\right], \mu_{i}^{t} \mid\left\{z_{i}^{t}, s_{i}^{t-1}=1\right\} \sim \operatorname{Normal}(0,1)
$$

where 1 is an indicator function. $z_{i}^{t}$ must contain variables observed at time $t$ for all individuals with $s_{i}^{t-1}=1 . z_{i}^{t}$ may, for instance, include the variables in $X_{i}^{t-1} \cdot \eta_{t}$ refers to the parameters associated with $z_{i}^{t}$ and $\mu_{i}^{t}$ is the error term of the selection equation. We will also include some exclusion restrictions (see Section 3.2).

In order to estimate the model, we make the following two assumptions: First,

$$
\mathrm{E}\left(c_{i} \mid \bar{X}_{i}, \mu_{i}^{t}\right)=\bar{X}_{i}^{\prime} \pi+\xi_{t} \mu_{i}^{t}
$$


where $\bar{X}_{i}$ are the sample individual averages of $X_{i}^{t}$ and $\pi$ and $\xi_{t}$ are sets of parameters to be estimated. This assumption is basically an adapted version of the "Mundlak" approach (cf. assumption 17.7c of Wooldridge 2002, page 583). Second,

$$
\mathrm{E}\left(u_{i}^{t} \mid c_{i}, X_{i}, z_{i}^{t}, \mu_{i}^{t}, s_{i}^{t-1}\right)=\mathrm{E}\left(u_{i}^{t} \mid \mu_{i}^{t}\right)=\rho_{t} \mu_{i}^{t}
$$

where $\rho_{t}$ is a parameter to be estimated (cf. equation 17.60 of Wooldridge 2002, page 586). Equations 3, 5, 6 imply that:

$$
\mathrm{E}\left(H_{i}^{t} \mid X_{i}, \mu_{i}^{t}\right)=X_{i}^{t} \theta+\bar{X}_{i}^{\prime} \pi+\phi_{t} \mu_{i}^{t}
$$

where $\phi_{t}=\xi_{t}+\rho_{t}$. If we condition on $s_{i}^{t}=1$ instead of on $\mu_{i}^{t}$ (because $s_{i}^{t-1}=1$ when $s_{i}^{t}=1$, we do not have to condition on $\left.s_{i}^{t-1}=1\right)$, we get:

$$
\begin{gathered}
\mathrm{E}\left(H_{i}^{1} \mid X_{i}\right)=X_{i}^{1}{ }^{\prime} \theta+\bar{X}_{i}^{\prime} \pi=W_{i}^{1}{ }^{\prime} \Theta \\
\mathrm{E}\left(H_{i}^{2} \mid X_{i}, s_{i}^{2}=1\right)=X_{i}^{2}, \theta+\bar{X}_{i}^{\prime} \pi+\phi_{2} \lambda\left(z_{i}^{2}{ }^{\prime} \eta_{2}\right)=W_{i}^{2}{ }^{\prime} \Theta \\
\mathrm{E}\left(H_{i}^{3} \mid X_{i}, s_{i}^{3}=1\right)=X_{i}^{3}, \theta+\bar{X}_{i}^{\prime} \pi+\phi_{3} \lambda\left(z_{i}^{3}{ }^{\prime} \eta_{3}\right)=W_{i}^{3} \Theta \\
\vdots \\
\mathrm{E}\left(H_{i}^{T} \mid X_{i}, s_{i}^{T}=1\right)=X_{i}^{T}, \theta+\bar{X}_{i}{ }^{\prime} \pi+\phi_{T} \lambda\left(z_{i}^{T}{ }^{\prime} \eta_{T}\right)=W_{i}^{T}{ }^{\prime} \Theta
\end{gathered}
$$

where $\lambda\left(z_{i}^{2}{ }^{\prime} \eta_{2}\right), \lambda\left(z_{i}^{3}{ }^{\prime} \eta_{3}\right), \ldots \lambda\left(z_{i}^{T}{ }^{\prime} \eta_{T}\right)$ are the inverse Mills ratios associated with the sample selection Eq. 4 for $t=2,3, \ldots T$,

$\Theta=\left(\theta^{\prime}, \pi^{\prime}, \phi_{2}, \phi_{3}, \cdots, \phi_{T}\right)^{\prime}, W_{i}^{1}{ }^{\prime}=\left(X_{i}^{1}, \bar{X}_{i}, 0,0, \cdots, 0\right)^{\prime}, \quad W_{i}^{2},=\left(X_{i}^{2}, \bar{X}_{i}\right.$, $\left.\lambda\left(z_{i}^{2}{ }^{\prime} \eta_{2}\right), 0, \cdots, 0\right)^{\prime}, W_{i}^{3}{ }^{\prime}=\left(X_{i}^{3},{ }^{\prime}, \bar{X}_{i}^{\prime}, 0, \lambda\left(z_{i}^{3}{ }^{\prime} \eta_{3}\right), \cdots, 0\right)^{\prime}$, and $W_{i}^{T}{ }^{\prime}=\left(X_{i}^{T}, \bar{X}_{i}^{\prime}\right.$, $\left.0,0, \cdots, \lambda\left(z_{i}^{T}, \eta_{T}\right)\right)^{\prime}$. It now follows that pooled OLS of $H_{i}^{t}$ on $X_{i}^{t}, \overline{X_{i}}, d 2_{i} \widehat{\lambda}_{i}^{2}$, $d 3_{i} \widehat{\lambda}_{i}^{3}, \cdots, d T_{i} \widehat{\lambda}_{i}^{T}$ - where $d 2_{i}, d 3_{i}$, and $d T_{i}$ are wave dummies - yield consistent estimates for $\Theta$ (see Wooldridge 2002 for further details). The selection Eq. 4 is estimated using a Probit specification.

\subsubsection{Final empirical specification}

Using the same notation as before, the final empirical estimation is given by:

$$
\begin{aligned}
H_{i}^{t}= & \alpha+x_{i}^{t} \beta+\sum_{k=1}^{K_{1}} \mathrm{CV}_{i, k} \gamma_{k}+\sum_{k=1}^{K_{2}} \mathrm{PV}_{k}^{t} \delta_{k}+\sum_{k=1}^{K_{3}} f\left(a_{i}^{t}\right) \zeta_{k}+\overline{x_{i}} \pi+\phi_{2} d 2_{i} \widehat{\lambda}_{i}^{2} \\
& +\phi_{3} d 3_{i} \widehat{\lambda}_{i}^{3}+\cdots+\phi_{T} d T_{i} \widehat{\lambda}_{i}^{T}+\omega_{i}+u_{i}^{t}
\end{aligned}
$$

Since we use a two-step estimation procedure, we have to correct the standard errors resulting from our analyses. We do that using the formulae of Wooldridge (2002, section 12.5). A detailed explanation of the computation of the standard errors is available upon request. The obtained standard errors are robust to the presence of heteroscedasticity and autocorrelation. STATA is used to perform the calculations. 


\subsubsection{Statistical checks}

Omitted relevant macrovariables Excluding possibly important macrovariables may result in "spurious" associations between health and the included macrovariables. This is because many macrovariables typically exhibit a clear trend and this trend could be related with trends in health. With respect to the contemporaneous and early life conditions, we address the "spurious regression" problem as follows: we add a linear "calendar year" term to model Eq. 9. Note that we would end up in an observationally equivalent model if we would replace calendar year by year of birth because of the identity: calendar year = year of birth + age. Obviously, we could not include "year of birth" and "calendar year" at the same time because of the linearity constraint with age.

Then, we check whether the coefficients of the cohort and period variables ( $\mathrm{CV}$ and $\mathrm{PV})$ dramatically change by the addition of the linear trend variable. Moreover, we check whether the coefficient of the linear trend variable is significant. If it is insignificant, we do not find overwhelming evidence against the null hypothesis that macroindicators in model Eq. 9 appropriately describe the cohort and period effects.

There is an alternative way of checking whether we are able to explain most of the cohort and period effects: model Eq. 9 can be tested against a fully saturated model. This fully saturated model can be represented in several ways, e.g., by adding an arbitrary set of $\left(C-K_{1}-2\right)$ cohort dummies (where $C$ is the number of birth cohorts in our sample) and $\left(T^{*}-K_{2}-1\right)$ time dummies (where $T^{*}$ denotes the number of years covered in our sample; in our sample, $C=29$ and $T^{*}=6$ ). The test of model Eq. 9 against the fully saturated model boils down to checking whether the additional time and cohort dummies are jointly significant. If not, we do not find strong evidence against the null hypothesis that macroindicators in model Eq. 9 effectively summarize the cohort and period effects.

Multicollinearity We also need to check whether our results are not driven by multicollinearity problems between the right-hand-side variables. Multicollinearity of regressors does not only entail the problem of high variances of the individual coefficient estimates but also the problem that one may obtain large coefficient estimates (in absolute vales) that are spuriously significant. To check for multicollinearity problems, we compute the highest variance inflation factors (VIF) and the average VIF. The VIF of a particular right-handside variable $j$-th, say female, is equal to $1 /\left(1-R_{j}^{2}\right)$, where $R_{j}^{2}$ denotes the $R^{2}$ obtained from regressing the variable $j$-th on the other explanatory variables. A high VIF could indicate severe multicollinearity problems. Chatterjee et al. (2000) have formulated some rule of thumb for the VIF. According to these rules, there is evidence of multicollinearity (1) if the largest VIF is greater than 10 and (2) if the mean of all the VIFs is considerably larger than 1.

Nonseparability of the APC effects In model Eq. 9, we assume that APC effects are separable. To check this assumption, we follow an approach 
developed by MaCurdy and Mroz (1995), Gosling et al. (2000), and Fitzenberger et al. (2001). Say we want to test the nonseparability of age and cohort effects in model Eq. 9. We revised this model by replacing the period variables PV by a full set of calendar year dummies in order to saturate the cohort, period, and age dimension of the model. In order to test the hypothesis of uniform growth in functional limitations, we take the first derivative of the revised version of model Eq. 9 with respect to age, keeping year of birth constant, and add four interaction terms:

$$
a t^{*}, a t^{* 2}, a^{2} t^{*}, a^{2} t^{* 2}
$$

where $a$ is age and $t^{*}$ denotes calendar year. One arrives at the nonseparable variant of the revised version of model Eq. 9 by integrating these four interaction terms Eq. 10 keeping year of birth constant. Consider, for instance, the interaction term $a * t^{*}$. This interaction term can be rewritten as $a(c+a)$, where $c$ is year of birth. The integral of this interaction term is equal to $c a^{2} / 2+a^{3} / 3$.

Basically, if the four interaction terms are not jointly statistically significant, we do not find evidence of nonseparability in APC effects. Given the short time dimension of our dataset, we did not consider interaction terms of higher order in age or time (e.g. $\left.t^{* 3} a^{3}\right)$.

To conclude this section, it can be stated that, if we succeed in correcting for the effects of spurious correlation, of unobserved heterogeneity, and of selective attrition, and if the results are not driven by multicollinearity problems between the independent variables and if we cannot reject the hypothesis of separability of the APC effects, the included variables on early life and contemporaneous macroconditions may be considered to have a causal effect on health.

\section{Data and measures}

\subsection{Data}

The design and purposes of the LASA are described in detail elsewhere (Deeg and Westendorp de Serière 1994; Deeg et al. 1998). In this paper, we use a sample of initially 2,978 individuals born between 1909 and 1937 (29 cohorts). We use data from the first three waves conducted in 1992-1993, in 1995-1996, and in 1998-1999. Within each wave, one can distinguish two time periods (one for each calendar year). Table 1 summarizes the attrition in LASA.

First, we had to exclude respondents with a telephone interview as no information on functional limitations is available for them. Second, $85 \%$ of the loss on follow up (after exclusion of the telephone interviews) is due to health problems or death. This makes sample attrition very likely to be endogenous (Deeg et al. 2002). Third, given that only $15 \%$ of sample attrition is due to refusals, we do not make any distinction between attrition due to health problems and attrition due to refusals. 
Table 1 Pattern of attrition in the LASA study

\begin{tabular}{llrr}
\hline & Wave 1 & Wave 2 & Wave 3 \\
\hline Number of participants & 3,107 & 2,302 & 1,874 \\
Deceased & - & 417 & 344 \\
Too frail & - & 55 & 61 \\
Refusal & - & 90 & 64 \\
Telephone interview & - & 243 & 202 \\
\hline
\end{tabular}

\subsection{Measures}

Functional status Functional limitations are measured in the LASA study by self-reports on mobility activities in daily life. These self-reports include the ability of respondents to (1) cut their one own toenails, (2) walk up and down a 15-step staircase without stopping, and (3) make use of private or public transportation (McWhinnie 1981; Sonsbeek van 1988). Note that the choice of these three items has been done step-wise: in the LASA pilot study, nine items were used to measure functional ability and the selected three items were the most consistent ones to describe functional ability (Kriegsman et al. 1997; Smits et al. 1997). The score takes on the values 0, 1, and 2 when a test item is performed without any difficulty, with difficulties, or only with help, respectively. A score equal to 3 is given to the respondent when the activity cannot be performed. The total score is obtained by summing the three activity scores. The internal consistency of the three items is very good (Cronbach's alpha: 0.76); the test-retest reliability is excellent (weighted kappa's between 0.76 and 0.90) (Boshuizen et al. 2000).

Finally, note that functional status is self-reported and that the observed period effects could be explained by variations in the norms for subjective evaluations over time. Unfortunately, we cannot exclude this possibility. Moreover, strictly speaking, an ordered probability model should be used in order to take into account that our dependent variable is not measured on a metric scale. However, extending an ordered probit model by taking into account (correlated) unobserved heterogeneity and endogenous attrition is a very complex exercise. Therefore, we decided to refrain from using this.

Demographic and socioeconomic characteristics Age is characterized using a linear spline function with six knots at ages 55, 62.9, 69.4, 76.6, 83.8, and 91. In a sensitivity analysis, we extended the number of knots in order to make the age function more flexible. However, the results remain, to a large extent, similar.

Besides age, our model includes the following explanatory variables: gender $(0=$ "male," 1 = "female"), attained education level of the respondent (three dummies ranging from "elementary education not completed" to "university education"), household real net monthly income in 1,000 euro, occupational prestige of the longest job according to Sixma and Ultee (1983) (ranging from $0=$ "never had job" to 87 = "high prestige"), place of residence (two dummies for "North-East," and "South," with reference category "West"), and partner status ( 0 ="no partner," 1 = "partner"), and whether the respondent 
experienced a significant event (war, poverty, etc.) during childhood $(0=$ "no," 1 = "yes"). We also include a variable indicating missing values for this variable (4.4\% missing at wave 1$)$. In addition, we allow for an interaction effect between age and gender, as age effects on functional status may depend on gender. We also estimated models including interaction variables between gender and the age splines function. We could not reject the assumption that the coefficients of the interaction variables are the same. Therefore, we decided to work with a single interaction variable between gender and age.

Table 2 reports descriptive statistics on functional limitations and other demographic and socioeconomic characteristics at baseline.

After exclusion of cases with missing data for the dependent variables and/or the included demographic and socioeconomic characteristics, we end up with a sample of 2,767 persons. Six hundred sixty one persons only participate

Table 2 Descriptive statistics: Health, Demographic and Socioeconomic factors at baseline

\begin{tabular}{|c|c|c|}
\hline Variables & Response & Percent \\
\hline Number of respondents ${ }^{\mathrm{a}}$ & 2,991 & \\
\hline \multirow[t]{4}{*}{ Self reports on functional limitations } & 0 & 58.6 \\
\hline & $1-3$ & 25.0 \\
\hline & $4-6$ & 9.2 \\
\hline & $7-9$ & 7.2 \\
\hline \multirow[t]{6}{*}{ Age } & $55-60$ & 16 \\
\hline & $60-65$ & 17.5 \\
\hline & $65-70$ & 17 \\
\hline & $70-75$ & 15.3 \\
\hline & $75-80$ & 18 \\
\hline & $80-85$ & 16.2 \\
\hline \multirow[t]{6}{*}{ Year of birth } & 1909-1912 & 18.2 \\
\hline & 1913-1917 & 18.5 \\
\hline & $1918-1922$ & 15.1 \\
\hline & $1923-1927$ & 15.8 \\
\hline & $1928-1932$ & 16.7 \\
\hline & $1933-1937$ & 15.7 \\
\hline \multirow[t]{2}{*}{ Year of interview } & 1992 & 33.9 \\
\hline & 1993 & 66.1 \\
\hline Female & & 51.2 \\
\hline \multirow[t]{3}{*}{ Attained education level } & Low & 43.9 \\
\hline & Medium & 42.2 \\
\hline & High & 13.9 \\
\hline \multirow[t]{6}{*}{ Net monthly income (in Euro) } & $<625$ & 22.3 \\
\hline & $625-852$ & 22.4 \\
\hline & $853-1,080$ & 16.7 \\
\hline & $1,081-1,477$ & 18.9 \\
\hline & $1,478-1,932$ & 10.4 \\
\hline & $>1,933$ & 9.5 \\
\hline Occupational prestige longest job & Mean & 27.2 \\
\hline \multirow[t]{3}{*}{ Place of residence } & Northeast & 30.7 \\
\hline & South & 23.9 \\
\hline & West & 45.4 \\
\hline Partner status & No partner & 33.5 \\
\hline Significant event during childhood & No & 72.4 \\
\hline
\end{tabular}

after exclusion of missing values 
in wave 1, 423 persons participate in wave 1 and wave 2, and 1,683 persons participate in all three waves.

Macrodeterminants In his theoretical framework for health and survival, Schultz (1984) distinguishes five categories of macrodeterminants that may affect health instantaneously but also later in life: (1) market prices and wage rates to account for the general economic situation; (2) public (health care) programs; (3) climate and disease exposure; (4) availability of information on, for instance, hazardous or health-enhancing activities; and (5) infrastructure, like the availability of drinking water or sewage. Briefly, a consensus seems to have developed on the fact that especially bad nutrition and exposure to diseases during pregnancy, infancy, and childhood (Fridlizius 1989; Fogel 1994; Barker 1998; Bengtsson and Lindstrom 2003; Crimmins and Finch 2006) hinder the normal development of the body and cause permanent damages that affect health instantaneously and at later ages. This forms the framework underlying the selection of our macrovariables. Our macrodata are from Statistics Netherlands.

Instead of using market prices or wage rates (not available for all birthcohorts), we proxy the general economic conditions by the logarithm of the real gross national product (GNP) per capita during pregnancy, at age 1, at ages 1-5, at ages 5-15 (periods of growth of the children), and at ages 15-22 (at the entrance on the job market). Our analyses also account for the famine of unprecedented severity that the cities in the west of the Netherlands experienced in the winter of 1944/1945. This is to investigate whether experiencing malnutrition during childhood (at ages 12,16, and 18) affects functional status at older ages. Note that we cannot study the effect of experiencing a famine at ages under 7 since the youngest LASA respondents were born in 1937.

With respect to public programs, the Netherlands faced severe restrictions in availability in acute and long-term care facilities during the observation window (Portrait 2000). We include: (1) the number of hospital beds per 1,000 inhabitants aged 65 and above, (2) the number of nursing days in hospitals per 1,000 inhabitants aged 65 and above, (3) the average duration of stays in hospitals, (4) the number of persons in residential homes per 1,000 individuals aged 65 and above, (5) the number of nursing days in nursing homes per 1,000 inhabitants aged 65 and above, (6) the number of workers in home care organizations per 1,000 individuals aged 65 and above, and (7) the proportion of middle-aged females participating in the labor market as they are an important source of informal care of disabled older individuals. Finally, the Netherlands went through a rapid increase in work-related disability from the 1970s until 1990. This may have affected the reporting behavior for two main reasons. First, it became more and more accepted to be disabled. Second, individuals possibly overstated their disability status to have access to the generous disability schemes. To address this, we investigate whether the proportion of individuals participating in disability schemes when the 
respondent was aged $30-40,40-50$, and $50-60$ affect the trends in functional limitations.

Regarding climate exposure, cohorts that grew up during cold winters and rainy springs may have had worse living conditions and less access to (good-quality) food (Doblhammer and Vaupel 2001). To address this, we include as cohort variables average temperature in the winter at birth and at ages 1-5. Regarding exposure to diseases, we include the percentage of deceased individuals due to infectious diseases, due to tuberculosis, and due to cancer at birth of the respondent, and between ages 1 and 5. We also include infant mortality under age 1 . Influenza caused a dramatic epidemic in 1918 . We include dummy variables indicating whether the respondent was under age 5 and under age 14 in 1918.

Information availability is characterized using a variable indicating the average attained level of education of fathers at birth of the respondent and the average level of attained education level of children when the respondent was 14 years of age. Finally, regarding infrastructure, we could not find any good historic data on the availability of sewage and drinking water facilities. However, the major investments in public health were made in 1870-1900. Therefore, we can assume that all LASA respondents grew up in favorable conditions with respect to sewers and water supply.

In addition to the five categories of the Schultz framework, we should mention that our sample is conditional on survival up to the beginning of the observation window. A substantial part of the cohort effects may be muted since we only observe the fittest members of each cohort. Due to the design of the data, our conclusions with respect to cohort effects only concern individuals who survive until at least age 55. We attempt to correct our analyses for this survivorship bias by including variables indicating differences in prior death in successive cohorts. The four variables indicate the number of survivors to ages $1,15,40$, and 50 out of 100,000 individuals per year of birth and sex (Tabeau et al. 1994).

Table 3 provides information on most cohort variables and shows that the trends are as expected: decreasing infant mortality, a steady decline of the number of deaths due to infectious diseases and/or tuberculosis and of the infant mortality with the exception of the years around the first World War, a slight increase of the average education level of the father and of the children, an increasing GNP to 1921 slightly decreasing afterwards, and an increasing percentage of individuals with disability schemes after 1970 . Table 4 provides information on the period variables. It shows a decreasing availability of care services (except for the use of nursing homes) and an increasing female labor participation during the observation window.

Exclusion restrictions As we said before, our model includes two selection equations. The first (second) equation explains the attrition between waves 1 (2) and 2 (3). In those selection equations, we included the same age, cohort, 


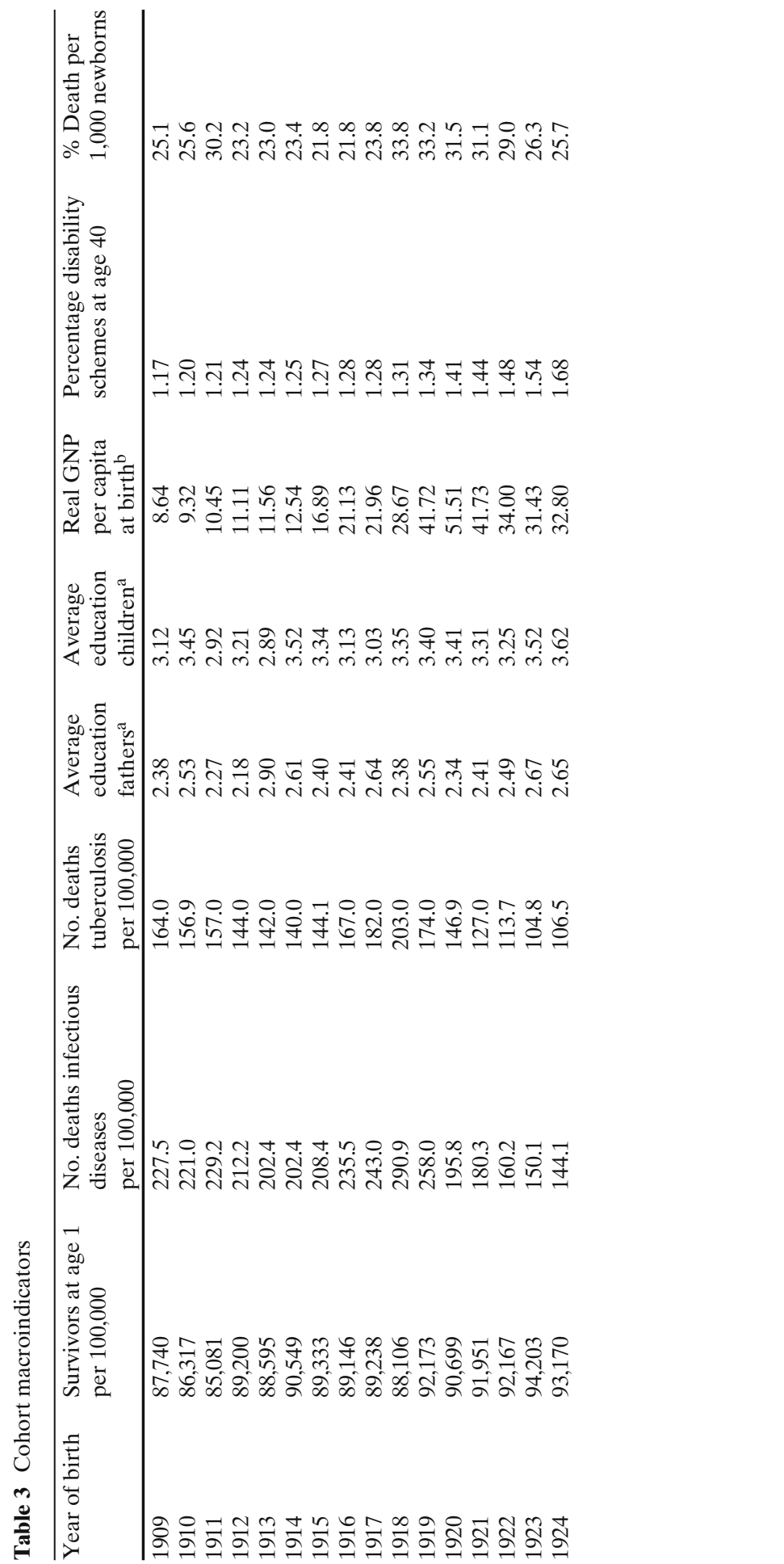




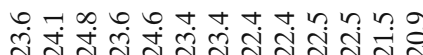

๓

-i-i d

ก

ले तै

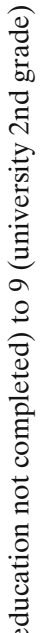

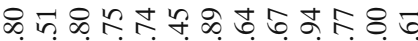

กิ

$\dot{m} \dot{m} \dot{m} \dot{m} \dot{m} \dot{m} \dot{m} \dot{m}$

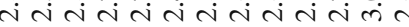

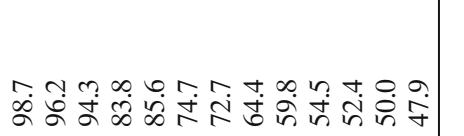

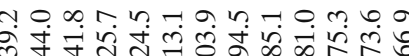

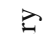

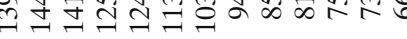

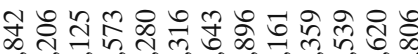

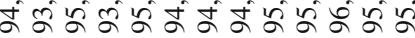


Table 4 Period macroindicators

\begin{tabular}{lllllll}
\hline Indicators & 1992 & 1993 & 1995 & 1996 & 1998 & 1999 \\
\hline $\begin{array}{c}\text { Nb hospital beds per } \\
\quad 1,000 \text { inhabitants }\end{array}$ & 4.2 & 4.1 & 3.9 & 3.8 & 3.7 & 3.6 \\
$\begin{array}{c}\text { Nb nursing days in hospitals } \\
\text { per 1,000 inhabitants }\end{array}$ & 1.1017 & 1.0756 & 1.0230 & 1.0032 & 0.9448 & 0.8845 \\
$\begin{array}{c}\text { Nb of residential home } \\
\text { dwellers per 1,000 65+ }\end{array}$ & 127 & 124 & 119 & 117 & 108 & 107 \\
$\begin{array}{c}\text { Nb nursing days in nursing } \\
\text { homes per 1,000 65+ }\end{array}$ & 9.6227 & 9.6589 & 9.7545 & 9.7581 & 9.7028 & 9.57 \\
$\begin{array}{c}\text { Nb of home care workers } \\
\text { per 1,000 65+ }\end{array}$ & 0.02534 & 0.02501 & 0.02438 & 0.02374 & 0.02399 & 0.02375 \\
$\begin{array}{c}\text { Percentage working } \\
\text { middle-aged females }\end{array}$ & 34.76 & 34.81 & 41.44 & 42.31 & 45.8 & 47.07 \\
\hline
\end{tabular}

and background characteristics as in the health equations. Moreover, we add a time dummy that indicates whether the respondent participates in the second time period within a wave.

Finally, we have to come up with variables that explain attrition due to mortality, being too ill, and refusals and that do not explain functional limitation outcomes, for instance variables indicating too little spare time to participate in the study. Those exclusion restrictions are crucial if we want to correct for attrition. We are in the fortunate position to have access to two convincing exclusion variables: a dummy indicating whether a female respondent is a member of a non-Roman catholic church (namely, mainly protestant) and a categorical variable indicating whether the participation in the LASA interview was enjoyable or not, ranging from 1 = "very unpleasant" to $5=$ "very pleasant." With respect to the latter, it is worth mentioning that the question is divided into two parts: the first part assessing whether the participation was tiring or not (which may be highly related to health status) and the second part assessing whether the respondent enjoyed the participation. The second part is much less likely to be associated with health status, and is consequently used in our analyses. We found some empirical support for this claim further by comparing the reason of attrition ("deceased," "too frail," "refusal") and the appreciation assessment of participation in LASA. It appears that respondents who stay in the sample, on average, appreciate the LASA questionnaire in the same way as those who leave the sample due to health reasons ("deceased," or "too frail"). Those respondents who refuse to participate in the next wave found participation in LASA significantly less enjoyable than the other groups. For instance, $44 \%$ of the respondents, who refused to participate in the third wave, found participation in the second wave (very) unpleasant. The corresponding percentage for stayers and for those who leave the sample due to health reasons ("too frail," "deceased") is equal to 23.

In the empirical part, we converted the latter variable into five dummies (enjoy1 until enjoy5). Moreover, we constructed additional exclusion variables by interacting the dummy variables "enjoy" with the binary variable "female," and with the dummy variable, which indicates whether the respondent 
participates in the second time period within a wave. We only retain in the final specification of the selection equations the significant interaction terms, namely, female*enjoy2, female*enjoy3, and the dummy for the second period in the wave *enjoy3. One could possibly argue that the exclusion restrictions described above mainly explain attrition due to refusals, and not other attrition processes due to health problems. We also experimented with additional variables such as categorical variables indicating the number of children, the number of grand-children, whether the respondent currently has a paid job, and the degree of participation in social organizations. These variables do not predict attrition. In total, we have eight exclusion restrictions for each selection equation.

\section{Results}

All specifications reported in Table 5 are based on model Eq. 9. Specification a includes gender, the interaction variable "age*gender," a linear spline function in age, cohort variables, and a full set of year dummies. Specification b differs from specification a in the sense that we explicitly model the period effects as well. The modeling of the age, cohort, and period effects is similar in specifications b and c; however, specification c is corrected for differences in demographic and socioeconomic characteristics, and specification $b$ is not.

Before commenting on the results, it is worth mentioning that, to decide whether we should correct for selective attrition or not, we have performed the test on selective attrition suggested by Wooldridge (2002, p.581) in all specifications (full results available upon request). The selection dummy $s_{i}^{t+1}$ was negative and very statistically significant, showing that respondents who remain in the LASA study report on average less functional limitations than the attritioners. This indicates that, to get consistent parameter estimates, one needs to control for selective attrition. We do that using the techniques derived in Section 2.2 to correct for selective attrition in the context of a random effects linear model with unobserved heterogeneity. We have also estimated the attrition bias fixed effects model of Wooldridge (2002). In this model, the cohort effects are subsumed in the individual effects and the time effects are modeled by means of macroindicators. In this way, we were able to check whether our approach and that of Wooldridge yielded similar estimates for the age coefficients. From our sensitivity analysis, this appeared to be the case (results are available upon request).

The estimation results of the exclusion restrictions included in the two selection equations associated with specifications $\mathrm{a}, \mathrm{b}$, and $\mathrm{c}$ are reported in Table 6 (see Section 3.2 for a description of the exclusion restrictions).

Note that the exclusion variables predict participation to LASA in successive waves: female members of a non-Roman catholic church and individuals who enjoyed the participation in the first (second) wave were more likely to participate in the second (third) wave than others. Moreover, females who experienced the LASA interview as unpleasant or not particularly pleasant 
Table 5 Estimation results model (9) on Self-reported Functional Limitations (first part)

\begin{tabular}{|c|c|c|c|}
\hline & Spec. a & Spec. b & Spec. c \\
\hline Inverse Mills ratio $(t=2)$ & $\begin{array}{c}-0.653 * \\
(0.38)\end{array}$ & $\begin{array}{c}-0.513^{* * *} \\
(0.21)\end{array}$ & $\begin{array}{r}-0.312 \\
(0.20)\end{array}$ \\
\hline Inverse Mills ratio $(t=3)$ & $\begin{array}{c}-0.935^{*} \\
(0.51)\end{array}$ & $\begin{array}{l}-1.372^{* * * *} \\
(0.49)\end{array}$ & $\begin{array}{l}-0.924 * * \\
(0.45)\end{array}$ \\
\hline Age spline $[55,63)$ & $\begin{array}{c}-0.0058 \\
(0.02)\end{array}$ & $\begin{array}{c}-0.0080 \\
(0.02)\end{array}$ & $\begin{array}{c}-0.0047 \\
(0.02)\end{array}$ \\
\hline Age spline $[63,69)$ & $\begin{array}{l}0.0172 \\
(0.02)\end{array}$ & $\begin{array}{l}0.0145 \\
(0.02)\end{array}$ & $\begin{array}{l}0.0062 \\
(0.02)\end{array}$ \\
\hline Age spline $[69,76)$ & $\begin{array}{l}0.0672 * * * \\
(0.02)\end{array}$ & $\begin{array}{l}0.0681 * * * \\
(0.02)\end{array}$ & $\begin{array}{l}0.0558 * * \\
(0.02)\end{array}$ \\
\hline Age spline $[76,84)$ & $\begin{array}{l}0.191 * * * \\
(0.02)\end{array}$ & $\begin{array}{l}0.192 * * * \\
(0.02)\end{array}$ & $\begin{array}{l}0.171 * * * \\
(0.02)\end{array}$ \\
\hline Age spline [84) & $\begin{array}{l}0.323^{* * *} \\
(0.06)\end{array}$ & $\begin{array}{l}0.341 * * * \\
(0.06)\end{array}$ & $\begin{array}{l}0.324 * * * \\
(0.06)\end{array}$ \\
\hline Period dummy 1993 & $\begin{array}{l}0.205^{* * *} \\
(0.08)\end{array}$ & & \\
\hline Period dummy 1995 & $\begin{array}{r}0.215 \\
(0.15)\end{array}$ & & \\
\hline Period dummy 1996 & $\begin{array}{l}0.407 * * \\
(0.16)\end{array}$ & & \\
\hline Period dummy 1998 & $\begin{array}{r}0.130 \\
(0.18)\end{array}$ & & \\
\hline Period dummy 1999 & $\begin{array}{l}0.435^{* *} \\
(0.20)\end{array}$ & & \\
\hline Female & $\begin{array}{l}-3.981 * * * \\
(0.59)\end{array}$ & $\begin{array}{l}-3.902 * * * \\
(0.59)\end{array}$ & $\begin{array}{l}-3.882 * * * \\
(0.64)\end{array}$ \\
\hline Female * Age & $\begin{array}{l}0.0662 * * * \\
(0.009)\end{array}$ & $\begin{array}{l}0.0652^{* * * *} \\
(0.009)\end{array}$ & $\begin{array}{l}0.0613 * * * \\
(0.009)\end{array}$ \\
\hline $\begin{array}{l}\% \text { of deaths due to Tuberculosis } \\
\text { in year of birth respondent }\end{array}$ & $\begin{array}{r}0.0025 \\
(0.003)\end{array}$ & $\begin{array}{r}0.0027 \\
(0.003)\end{array}$ & $\begin{array}{r}0.0023 \\
(0.003)\end{array}$ \\
\hline $\begin{array}{l}\text { Nursing days in hospitals per } \\
1,000 \text { individuals aged } 65+\end{array}$ & $(0.93)$ & $\begin{array}{l}-2.103^{* *} \\
(0.91)\end{array}$ & $-1.930 * *$ \\
\hline
\end{tabular}

were more likely to quit the LASA sample than males who felt similarly. Finally, the LASA participants who experienced the LASA interview as not particularly pleasant were more likely to quit the LASA sample when they were interviewed in the second time period of each wave instead of in the first time period of each wave. The $\chi^{2}$ tests (eight degrees of freedom) are reported in Table 5 and show that the exclusion variables are jointly significant in both selection equations. We admit, however, that the $\chi^{2}$ values are not that high, indicating that the exclusion restrictions are not really powerful.

\subsection{Specification a}

The estimated parameters associated with the inverse Mills ratios are all negative and significant at the $10 \%$ level. This result indicates that the unobservables determining attrition are negatively correlated with those determining individual health status. It is well-known that the Heckman correction procedure is very sensitive to parametric assumptions and that, for a few 
Table 5 (Continued)

\begin{tabular}{|c|c|c|c|}
\hline & Spec. a & Spec. b & Spec. c \\
\hline Medium educated $^{\mathrm{a}}$ & & & $\begin{array}{l}-0.276^{* * *} \\
(0.09)\end{array}$ \\
\hline High educated & & & $\begin{array}{r}-0.157 \\
(0.14)\end{array}$ \\
\hline Partner status & & & $\begin{array}{c}-0.0897 \\
(0.09)\end{array}$ \\
\hline Real income (in 1.000 euros) & & & $\begin{array}{c}-0.0039 \\
(0.07)\end{array}$ \\
\hline Real income & & & $\begin{array}{l}-0.658^{* * * *} \\
(0.11)\end{array}$ \\
\hline Occupational prestige & & & $\begin{array}{c}-0.0029 \\
(0.00)\end{array}$ \\
\hline Childhood event & & & $\begin{array}{l}0.343 * * * \\
(0.09)\end{array}$ \\
\hline Dummy childhood event & & & $\begin{array}{l}1.972 * * * \\
(0.32)\end{array}$ \\
\hline Living in northeast provinces ${ }^{b}$ & & & $\begin{array}{c}0.142 \\
(0.088)\end{array}$ \\
\hline Living in south provinces & & & $\begin{array}{r}0.0055 \\
(0.096)\end{array}$ \\
\hline Constant & $\begin{array}{r}0.473 \\
(1.01)\end{array}$ & $\begin{array}{l}2.988^{*} \\
(1.72)\end{array}$ & $\begin{array}{l}3.391 * \\
(1.78)\end{array}$ \\
\hline$p$ value $\chi^{2}$-test Mills ratios & 0.135 & 0.020 & 0.123 \\
\hline$p$ value $\chi^{2}$-test linear age spline & 0 & 0 & 0 \\
\hline$p$ value $\chi^{2}$-test time variables & 0.0345 & 0.0233 & 0.0345 \\
\hline Adjusted $R^{2}$ & 0.257 & 0.256 & 0.282 \\
\hline Number observations & 6,556 & 6,556 & 6,025 \\
\hline Highest VIF & 78.35 & 77.57 & 85.76 \\
\hline Average VIF & 17.45 & 17.40 & 10.93 \\
\hline $\begin{array}{l}\chi^{2} \text {-value Exclusion restrictions } \\
\text { first selection equation }\end{array}$ & 46.20 & 46.20 & 40.05 \\
\hline $\begin{array}{l}\chi^{2} \text {-value Exclusion restrictions } \\
\text { second selection equation }\end{array}$ & 35.69 & 35.69 & 34.39 \\
\hline $\begin{array}{l}\chi^{2} \text {-value Misspecification test } \\
\text { against fully saturated model }\end{array}$ & 23.61 & 34.04 & 28.96 \\
\hline $\begin{array}{l}p \text { value Misspecification test against } \\
\text { fully saturated model }\end{array}$ & 0.598 & 0.279 & 0.520 \\
\hline
\end{tabular}

Standard errors in parentheses

$* p<0.1 ; * * p<0.05 ; * * * p<0.01$

${ }^{a}$ Reference category is low educated

${ }^{\mathrm{b}}$ Reference category is western provinces

observations, the inverse Mills ratio might take on extreme large values. Those observations could have a huge leverage on the estimated coefficients corresponding to the inverse Mills ratios. In case of specification a, the maximum values of the two inverse Mills ratios are not that large (1.43613 and 1.234557). Moreover, we have investigated whether the estimation results of model 9 are strongly affected by the presence of some outlying inverse Mills ratios. This does not seem to be the case. Detailed results of sensitivity analysis are available upon request. 
Table 6 The sample selection equations associated with specifications a, b, and c of Table 5

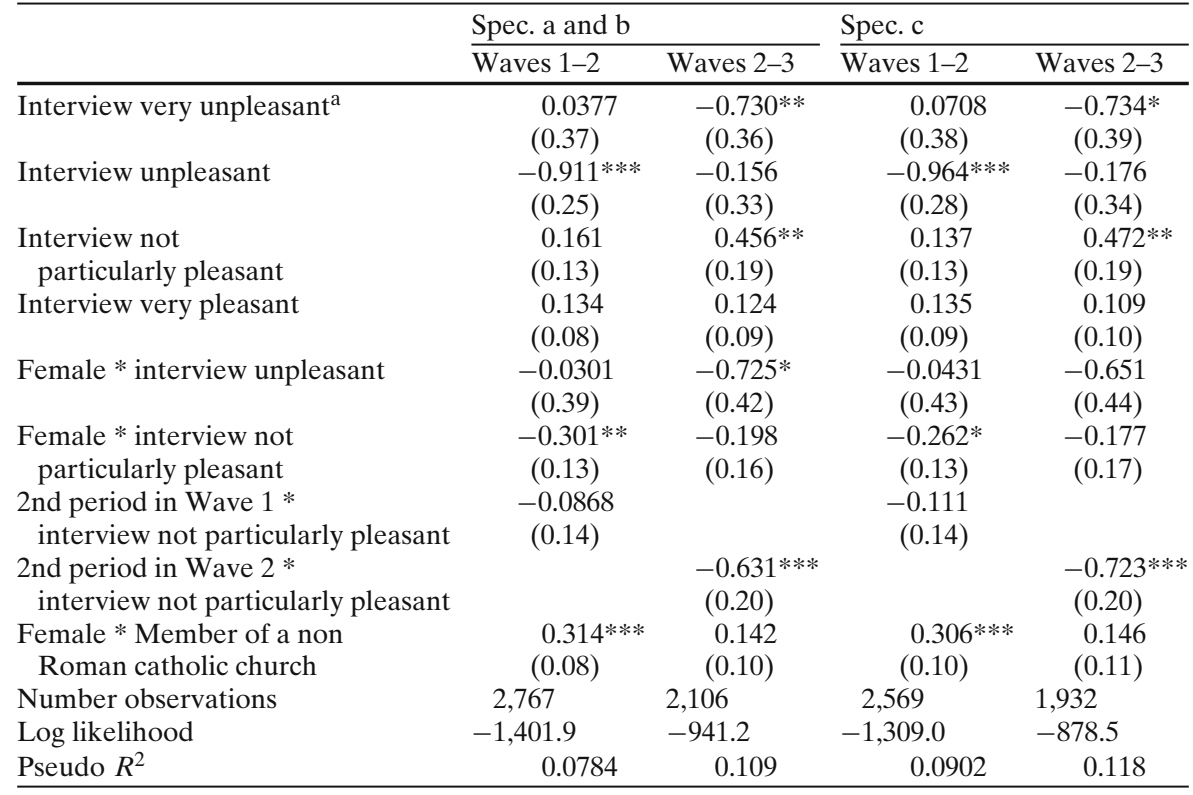

We only report the coefficient estimates associated with the exclusion restrictions

Standard errors in parentheses

$* p<0.1 ; * * p<0.05 ; * * * p<0.01$

${ }^{a}$ Reference category is interview pleasant

The estimated age spline parameters appear to be jointly significant $\left(\chi^{2}\right.$ test $=243.6$ ). The parameters of the age spline, which can be interpreted as ageinterval-specific slopes, show a highly nonlinear relationship between age and functional limitations: the functional limitations indicator increases at a faster rate as people become older. Note that the $H_{0}$ that functional limitations are a linear function of age (i.e., the five spline coefficients are the same) is rejected at the $1 \%$ level: $\chi^{2}(4)=88.05$.

In a preliminary analysis, we estimated a specification including step-wise all cohort variables described in Section 3.2. We could not find any strong evidence of cohort effects. The variable that had the highest explanatory power ( $t$ value equal to 0.91 ) was the variable indicating the percentage of deaths due to tuberculosis in the first year of the respondent. All other cohort variables had no or a lower explanatory power. To check whether the "tuberculosis" cohort variable should nevertheless be included in our model, we re-estimated all specifications without including the cohort variable and assessed whether the age and period parameters changed. The age parameters remained very similar: only the slope at ages 69-77 was a little bit steeper in the specification excluding the "tuberculosis" variable. However, the size of the period effects 
decreased slightly. Therefore, we decided to keep the "tuberculosis" variable in the final specifications.

The absence of significance of the cohort variables may be surprising in the light of the recent literature on the long-term health effects of early life conditions. Most results show long-term effects on chronic diseases and mortality at old ages (Kuh and Ben-Shlomo 2004). However, to our knowledge, there is no empirical evidence of long-term effects of exposure in early life on functional limitations at older ages.

The variables indicating prior mortality per cohort were also insignificant. This result may deserve an additional explanation. As mentioned in Section 3.2, our sample may suffer from survivorship bias. To control for this, we added in preliminary work a set of variables indicating differences in prior death in successive cohorts per gender (see Section 3.2 for a description of these variables). All parameter estimates associated with the mortality variables were not statistically significant, and the remaining parameter estimates were only very slightly affected by the inclusion of these variables.

A significant increasing trend is shown in specification a ( $p$ value equal to 0.0345 ): individuals report more functional limitations at the end of the 1990s, after correction for age and cohort effects. The estimated parameters of the dummy variable "female" and the interaction term between female and age show that females report on average more functional limitations than males from age 61 onwards. Moreover, the prevalence of functional limitations for females increased with age at a significantly higher rate than for males.

\subsection{Specification $b$}

In preliminary analyses, we estimated specification a, including step-wise all period variables described in Section 3.2. We find that the prevalence of selfreported functional limitations is significantly related to the restrictions in hospital care (characterized by the number of nursing days in hospital per capita).

Regarding this adverse period effect, a few explanations may be put forward. Individuals may experience (higher levels of) functional limitations for a longer period of time as the waiting period for, e.g., surgeries increased during the 1990s. Patients may also be discharged from hospitals earlier, which may also result in a deterioration of their functional status. We could not find any significant effects on functional status of the supply reductions in informal care, home care, and institutional care.

It is interesting to see that the parameters of the age splines, cohort, and gender variables are, to a large extent, similar in specifications a and b. Finally, note that the parameters associated with the inverse Mills ratios are again all negative and significant: the first one at a $5 \%$ level and the second one at a $1 \%$ level. Moreover, the inverse Mills ratios are jointly significant at the $5 \%$ level $(p$ value $=0.02)$. 


\subsection{Specification $\mathrm{c}$}

The coefficients of the APC variables are not much affected by the inclusion of the individual characteristics. Again, we do not find evidence that early life conditions affect functional limitations at older ages. However, the prevalence of functional limitations is found to increase in the 1990s, in part due to restricted access to hospital care.

After correction for differences in demographic and socioeconomic characteristics, the estimated parameters associated with the inverse Mills ratios remain negative. It is still important to correct for endogenous attrition: one of the Mills ratio is significant at the $5 \%$ level.

In a preliminary analysis, we excluded from our model the insignificant"Mundlak" variables. Note that two time-varying regressors are included in our model, namely, real net monthly income and partner status. We end up with one significant "Mundlak" variable (namely average income), which shows the need to correct for possible correlation between the unobserved individual effects and the time-varying right-hand-side variables.

The estimation results demonstrate that medium educated respondents report significantly less functional limitations than lower educated respondents. The fact that the estimated parameter associated with the highest educational class is not significant may be explained by the low number of individuals in this category (see Table 2). The parameter estimates associated with the income variables show that individuals with higher incomes report less functional limitations. One could interpret the average income as a proxy for permanent income and the coefficients corresponding to current income measures maybe the effect of transitory income. In that case, one can conclude that a higher permanent income results in a significantly lower level of functional limitations. Likewise, respondents for whom the longest job was a job with high prestige are less functionally disabled at older ages than others. We find some effect of the region (respondents in the northeast report more functional limitations than in the west). Strong negative effects on functional status of having experienced a significant event during childhood emerge. Finally, we do not find a significant effect of having a partner on the probability of having functional limitations.

\section{Sensitivity analysis}

\subsection{Omitted relevant macrovariables}

It is important to test whether the cohort and period effects are correctly specified. First, we included in previous work a linear "calendar year" term into specifications b and c of model Eq. 9 (see Section 2.2). As mentioned earlier, we could have included a linear "birth of year" term, but the two models are observationally equivalent. The estimates of the parameters associated with the age splines and the cohort variable "tuberculosis" were hardly affected 
in both specifications. The parameter associated with the period variable does not change dramatically. The estimate (standard error) of the coefficient corresponding to the period variable "nursing days in hospitals" decreases from $-2.103(0.93)$ to -3.197 (2.52). The coefficient associated with the cohort variable "\% death tuberculosis at birth" changes barely from $0.00278(0.00270)$ to $0.00272(0.00270)$.

Moreover, the estimate of the parameter associated with the linear trend was not statistically significant $(t$ value $=0.7$ in specification $\mathrm{b}$ and $t$ value $=$ 0.6 in specification c). Consequently, we excluded the time trend from the final specifications.

Second, we tested specifications $\mathrm{a}, \mathrm{b}$, and $\mathrm{c}$ against a fully saturated model. In specification a, we added 26 cohort dummies, and in specifications $\mathrm{b}$ and $\mathrm{c}$, 27 cohort dummies and three period dummies were included. The additional dummy variables were not jointly significant in all specifications (see Table 5). Therefore, we do not find overwhelming evidence against the null-hypothesis that the macroindicators included in specifications a, b, and c appropriately describe the cohort and period effects.

\subsection{Multicollinearity}

The results presented above may be driven by the high degree of multicollinearity between the variables. In order to check this, we first compute the highest VIFs and the average VIF and report them in Table 5. The largest VIF in specification a is equal to 78.35 and corresponds to the variable "female*age." It appears that the variables "female" and "female*age" are strongly correlated with each other: those variables have very high VIFs. As mentioned in Section 2.2, these variables could be spuriously significant. However, we think that we do not have to worry about the high VIFs of those two variables because the standard errors of the corresponding coefficient estimates are rather small. Apparently, there is sufficient sample variation in the variables gender and "sex*age." If we disregard the variables "female" and "female*age," then the variable indicating "tuberculosis" has the highest VIF, equal to 8.25. This value is not particularly high (see the rules of thumb presented in Section 2.2.4).

In specifications $\mathrm{b}$ and $\mathrm{c}$, we replace the time dummies by one period variable. The VIF of the right-hand-side variables (except for "female" and "female*age") are below 10. Again, the other age, cohort, and period variables are not strongly correlated with each other.

\subsection{Nonseparabilities of the APC effect}

We carried out the nonseparability test explained in Section 2.2.4. It appears that those four interaction terms are not jointly significant $\left(\chi_{4}^{2}=5.53\right.$; $p$ value $=0.24)$. In other words, we do not find evidence for nonseparabilities in APC effects. 


\section{Summary and conclusions}

This paper presents an approach that allows investigators to assess the role of early life and contemporaneous macroconditions in explaining self-reports on functional limitations later in life. In particular, we investigate the role of exposure to infectious diseases and economic conditions during infancy and childhood, as well as the effect of current health care facilities and economic conditions. Specific attention was paid to the impact on estimation results of omitted relevant macrovariables, unobserved heterogeneity, selective attrition, and multicollinearity of the included regressors. Note that this study is also related to the line of research dealing with the identification of APC effects. The empirical analysis is performed on the LASA. At the time of the study, there were only three waves available, and that certainly restricts the validity of our results. Interpretation of age effects should therefore be limited to the observed age span if we want to avoid out-of-sample predictions. For future studies, we recommend the coverage of longer time periods. We nevertheless would like to reemphasize that the purpose of this study is to propose an approach to thoroughly assess the effect of early life conditions and contemporaneous conditions on health later in life, which we applied to self-reports on functional limitations at older ages as a matter of illustration.

The main conclusions of the paper are that early life macroconditions do not explain self-reports on functional limitations at older ages. However, functional limitations are adversely affected by period effects. These period effects stem from the fact that the number of nursing days in hospital decreased in the 1990s.

Acknowledgements The Longitudinal Aging Study Amsterdam (LASA) is primarily supported by a long term grant from the Dutch Ministry of Health, Welfare and Sports. We thank the editor, three anonymous referees, and Adriaan Kalwij for helpful comments and suggestions.

Open Access This article is distributed under the terms of the Creative Commons Attribution Noncommercial License which permits any noncommercial use, distribution, and reproduction in any medium, provided the original author(s) and source are credited.

\section{References}

Almond DV (2006) Is the 1918 influenza pandemic over? Long-term effects of in utero influenza exposure in the post-1940 U.S. population. J Polit Econ 114(4):672-712

Alwin DF, McCammon RJ (2001) Aging, cohorts, and verbal ability. J Gerontol Soc Sci 56B(3):S151-S161

Barker DJP (1998) Mothers, babies, and health in later life, 2nd edn. Churchill Livingstone, Edinburgh

Bengtsson T, Lindstrom M (2003) Airborne infectious diseases during infancy and mortality in later life in southern Sweden, 1766-1894. Int J Epidemiol 32(2):286-294

van den Berg G, Lindeboom M, Portrait F (2006) Economic conditions early in life and individual mortality. Am Econ Rev 96(1):290-302

Boshuizen HC, Chorus AMJ, Deeg DJH (2000) Test-retest reliability of the OECD questionnaire for physical limitations. Tijdschr Gezondheidswet 78(3):172-179 (In Dutch) 
Chatterjee S, Hadi AS, Price B (2000) Regression analyses by example, 3rd edn. Wiley, New York

Crimmins EM, Finch CE (2006) Infection, inflammation, height, and longevity. Proc Natl Acad Sci U S A 103(2):498-503

Deeg DJH, Westendorp de Serière M (1994) Autonomy and well-being in the aging population, report from the Longitudinal Aging Study Amsterdam 1992-1993, 1st edn. VU University Press, Amsterdam

Deeg DJH, Beekman ATF, Kriegsman DMW, Westendorp de Serière M (1998) Autonomy and well-being in the aging population 2, report from the Longitudinal Aging Study Amsterdam 1992-1996, 1st edn. VU University Press, Amsterdam

Deeg DJH, van Tilburg T, Smit JH, de Leeuw ED (2002) Attrition in the Longitudinal Aging Study Amsterdam: the effect of differential inclusion in side studies. J Clin Epidemiol 55(4):319-328

Doblhammer G, Vaupel JW (2001) Lifespan depends on month of birth. Proc Natl Acad Sci U S A 98(5):2934-2939

Fitzenberger B, Hujer R, MaCurdy TE, Schnabel R (2001) Testing for uniform wage trends in West-Germany: a cohort analysis using quantile regressions for censored data. Empir Econ 26(1):41-86

Fogel R (1994) The relevance of Malthus for the study of mortality today: long-run influences on health, mortality, labor force participation, and population growth. In: Lindahl-Kiessling K, Lamberg H (eds). Population, economic development and the environment, 1st edn. Oxford University Press, Oxford, pp 231-261

Fridlizius G (1989) The deformation of cohorts. Nineteenth century mortality in a generational perspective. Scand Econ Hist Rev 37(3):3-17

Gosling A, Machin S, Meghir C (2000) The changing distribution of male wages in the U.K. Rev Econ Stud 67(4):635-666

Heckman J, Robb R (1985) Using longitudinal data to estimate age, period and cohort effects in earning equations. In: Mason W, Fienberg S (eds) Cohort analysis in social research beyond the identification problem, 1st edn. Springer, New York

Hoeymans N, Feskens EJM, van den Bos GAM, Kromhout D (1997) Age, time, and cohort effects on functional status and self-rated health in elderly men. Am J Public Health 87(10): $1620-1625$

Kapteyn A, Alessie R, Lusardi A (2005) Explaining the wealth holding of different cohorts: productivity growth and social security. Eur Econ Rev 49(5):1361-1391

Kuh D, Ben-Shlomo Y (2004) A life course approach to chronic disease epidemiology, 2nd edn. Oxford University Press, Oxford

Kriegsman DMW, Deeg DJH, van Eijk TM, Penninx BWJH, Boeke AJP (1997) Do disease specific characteristics add to the explanation of mobility limitations in patients with different chronic diseases? A study in the Netherlands. J Epidemiol Community Health 51(4): 676-685

Mackenbach JP (1996) The contribution of medical care to mortality decline: Mc Keown revisited. J Clin Epidemiol 49(11):1207-1213

MaCurdy TE, Mroz T (1995) Measuring macroeconomic shifts in Wages from cohort specifications. Stanford University and University of North Carolina

McWhinnie JR (1981) Disability assessment in population surveys: results of the OECD common development effort. Rev Épidémiol Santé Publique 29(4):413-419

Mason WH, Fienberg SE (1985) Cohort analysis in social research: beyond the identification problem, 1st edn. Springer, New York

Mundlak Y (1978) On the pooling of time series and cross section data. Econometrica 46(1):69-85

Nydegger CN (1981) On being caught up in time. Hum Dev 24(11):1-12

Perenboom RJM, Herten LM, Boshuizen HC, van den Bos GA (2004) Trends in disability-free life expectancy. Disabil Rehabil 26(7):377-386

Portrait F (2000) Long-term care services for the Dutch elderly—an investigation into the process of utilization. Thesis VU University Amsterdam, Amsterdam

Reynolds SL, Crimmins EM, Saito YS (1998) Cohort differences in disability and disease presence. Gerontologist 38(5):578-590

Roseboom TJ, Meulen van der JH, Osmond C, Barker DJP, Bleker OP (2001) Effects of prenatal exposure to the Dutch famine on adult disease in later life: an overview. Twin Res 4(5): 293-298 
Ruhm C (2008) Macroeconomic conditions, health and government policy. In: Schoeni RF, House JS, Kaplan GA, Pollack H (eds) Social and economic policy as health policy: rethinking Americas approach to improving health. Russell-Sage, New York (in press)

Schultz TP (1984) Studying the impact of household economic and community variables on child mortality. Child survival. Strategies for research. Popul Dev Rev 10:215-235 (Suppl)

Sixma H, Ultee WC (1983) Occupational prestige score for the Netherlands in the eighties. Mens Maatsch 58(1):360-382 (in Dutch)

Smits CHM, Deeg DJH, Jonker C (1997) Cognitive and emotional predictors of disablement in older adults. J Aging Health 9(2):204-221

Sonsbeek van JLA (1988) Methodological and substantial aspects of the OECD questionnaire regarding long-term limitations in physical functioning (in Dutch). Maandber Gezondh 6:4-17 (Central Bureau of Statistics, Netherlands)

Tabeau E, Tabeau A, van Poppel F, Willekens F (1994) Mortality by cohorts. Netherlands Interdisciplinary Demographic Institute (NIDI) Working papers

Verbeek M, Nijman T (1992) Testing for selectivity bias in panel data models. Int Econ Rev 33(3):681-703

Wooldridge JM (2002) Econometric analysis of cross section and panel data, 1st edn. MIT, Cambridge 